\title{
Polymerase chain reaction for the diagnosis of herpesvirus infections in dermatology
}

\author{
Analysis of clinical data
}

\author{
Verena Schremser · Lukasz Antoniewicz · Erwin Tschachler · Alexandra Geusau
}

Received: 1 October 2019 / Accepted: 15 November 2019 / Published online: 9 December 2019

(C) The Author(s) 2019

\begin{abstract}
Summary
Background Rapid identification of human herpesviruses from lesion swabs is necessary for timely initiation of antiviral treatment, especially with infections involving neonates and immunocompromised individuals. The aim of the study was to investigate the results of an in-house polymerase chain reaction (PCR) test for herpesviruses in patients with symptoms suggestive for a herpesvirus infection.

Patients and methods In this single center retrospective study the results of 3677 lesion swab specimens tested for human herpes simplex virus 1 and 2 (HSV 1 and 2) and varicella zoster virus (VZV) were analyzed in the context of data sheets giving details of the suspected diagnosis, medical history as well as the demographic data of the patients. The PCR procedures for cytomegalovirus (CMV), Epstein-Barr virus (EBV) and human herpes virus 8 (HHV-8) were applied on special occasions.

Results Of the samples 3369 (91.6\%) were swabs and a minority were tissue or blood samples. Of the 3015 samples tested for HSV-1, HSV-2 and VZV concomitantly, $52.3 \%$ were positive for at least one of these viruses. Clinically distinct conditions, such as herpes zoster and varicella had a high rate of positive PCR results, ranging from $81 \%$ to $88 \%$, respectively. Among
\end{abstract}

V. Schremser, MD · Assoc. Prof. Dr. A. Geusau, MD (凶) Department of Dermatology, Medical University of Vienna, Waehringer Guertel 18-20, 1090 Vienna, Austria

alexandra.geusau@meduniwien.ac.at

\section{Antoniewicz, MD}

Dept. of Clinical Sciences, Karolinska Institutet at Danderyds University Hospital, Stockholm, Sweden

\section{E. Tschachler, MD}

Research Department of Biology and Pathobiology of the Skin, Medical University of Vienna, Vienna, Austria
HSV-2 positive samples, $23.7 \%$ derived from human immunodeficiency virus (HIV) positive patients, in contrast to the $10.8 \%$ originating from immunocompetent patients, the difference being statistically significant $(p<0.002)$. The HSV-2 was detected more often in women than in men.

Conclusion Distinct clinical diagnoses have a high correlation rate with positive PCR results. A significantly higher number of HSV-2 positive results were found in HIV positive patients and in women.

Keywords Polymerase chain reaction · Virology • Herpetic skin manifestations · Herpes simplex · Immunosuppression

\section{Introduction}

Human herpesvirus (HHV) infections are common worldwide. Clinically, herpes simplex virus 1 and 2 (HSV-1 and HSV-2, respectively) and varicella zoster virus (VZV) result in a range of diseases involving the skin and mucous membranes, occasionally leading to severe complications, such as herpetic neuralgia and herpes encephalitis. Due to similarities in the clinical presentations of infections caused by these three herpesviruses, a clinical diagnosis needs to be confirmed by laboratory testing and direct proof of the pathogen to prevent misdiagnosis and a delay in the initiation of appropriate antiviral treatment. Therefore, early diagnosis with a highly sensitive method is mandatory [1]. Traditional laboratory methods for the diagnosis of cutaneous and mucocutaneous HSV-1, HSV-2, and VZV infections include the Tzanck smear, direct fluorescent assay (DFA), and cell culture. Although viral culture has been considered the gold standard test, several reports have been published on the much higher sensitivity of polymerase chain reaction (PCR) assays for detecting HSV and VZV 
over the traditional methods [2-6]. In the year 2000 when a herpes PCR test was not yet commercially available, an in-house PCR amplification technique for the detection of HSV-1, HSV-2, VZV as well as other members of the herpesvirus family, such as cytomegalovirus (CMV), Epstein-Barr virus (EBV) and human herpesvirus 8 (HHV-8), were established at the Department of Dermatology, Medical University of Vienna and further employed on a routine level for samples directly acquired from active lesions.

The purpose of this retrospective study was to analyze the correlation of the PCR results and the clinical diagnoses supplied on standardized data sheets giving details on individual-related facts, medical history and demographic data of the patients. Furthermore, the study aimed to depict the distribution of the various herpesviruses detected in different patient populations with different clinical diagnoses.

\section{Material and methods}

\section{Study population and data collection}

In this single center study, test results of swab samples taken from presumably herpesvirus-associated lesions on the skin and mucous membranes which had been analyzed by a routine PCR testing for HSV-1, HSV-2 and VZV, were retrospectively evaluated at the Department of Dermatology, Medical University of Vienna. An in-house herpes PCR technique was performed on a total of 3677 samples collected during a period of 4 years. A standardized data sheet was compiled of each case giving details of the suspected diagnosis, sample site, the test requested as well as demographic data of the patients including age, gender and immune status. Several types of viral genome were investigated in each sample concomitantly, in particular HSV 1 and 2, VZV, whereas CMV, EBV and HHV-8 only when requested by the clinician. The results of the PCR analysis documented on these data sheets were anonymized for this analysis. Missing data were collected from archived patient charts. Finally, the clinical diagnoses were categorized based on similarities of the clinical manifestation mentioned on the order form. The data were then transferred to SPSS (Statistical Package for the Social Sciences, IBM ${ }^{\circledR}$ SPSS Statistics ${ }^{\circledR}$, version 24, Chicago, IL, USA).

Sample and specimen collection: Using a sterile cotton tip or disposable scalpel, swabs from vesicles, pustules, erosions on skin and mucous membranes were sampled after gently removing the roof of the vesicle or pustule in order to collect the fluid and cellular material at the base of the lesion. If the site was ulcerated, crusts of the lesions were removed. The obtained material was applied on a simple slide and passed to the laboratory. The DNA from biopsy samples was transferred to the laboratory in sterile tubes.
DNA extraction: From the slides, the material was scraped off and transferred to sterile containers suspended in $1.0 \mathrm{ml}$ sterile $\mathrm{H}_{2} \mathrm{O}$, boiled for $15 \mathrm{~min}$ and stored at $+4 \mathrm{C}$. For all samples, DNA was extracted using a DNA extraction kit (Qiagen DNeasy blood and tissue kit [QIAGEN, Hildesheim, Germany]), a procedure carried out according to the manufacturer's instruction.

\section{PCR amplification for HSV1, HSV2, VZV, B-actin:}

The amplification reaction was carried out in $50 \mu \mathrm{l}$ reaction mixture, containing $5 \mu \mathrm{l}$ of $10 \mathrm{X}$ PCR reaction buffer, $1 \mu \mathrm{l}$ of $10 \mathrm{mM}$ dNTPs, $3 \mu \mathrm{l} \mathrm{MgCl}_{2}, 2.5 \mu \mathrm{l}$ of $10 \mathrm{pmol}$ forward primers, $2.5 \mu \mathrm{l}$ of $10 \mathrm{pmol}$ reverse primers, $0.1 \mu$ of $5 \mathrm{U} / \mu \mathrm{l}$ Red hot Taq deoxyribonucleic acid (DNA) polymerase (Thermo Scientific, Thermo Fisher Scientific, Inc., Waltham, MA, USA) and $5 \mu \mathrm{l}$ DNA samples (100 ng). Amplification was carried out with a thermal profile at $94^{\circ} \mathrm{C}$ for $4 \mathrm{~min}$ initial denaturation then 40 cycles $\left(94^{\circ} \mathrm{C}\right.$ for $1 \mathrm{~min}, 58^{\circ} \mathrm{C}$ for $30 \mathrm{~s}$ and $72^{\circ} \mathrm{C}$ for $1.5 \mathrm{~min}$ ) amplification with a final extension of $72^{\circ} \mathrm{C}$ for $8 \mathrm{~min}$. The primer pair (B-actin-s and B-actin-as) was used to amplify (570 base pair) human housekeeping gene B-actin, the primer pair (HSV1-s and HSV1-as) was used to amplify (448 base pair) HSV1 DNA, the primer pair (HSV2-s and HSV2as) was used to amplify (239 base pair) HSV2 DNA, the primer pair (VZV-s and VZV-as) was used to amplify (326 base pair) fragment of VZV DNA.

PCR amplification for HV8, CMV and EBV: The amplification reaction was performed as described above. Amplification was carried out with a thermal profile at $94^{\circ} \mathrm{C}$ for $4 \mathrm{~min}$ initial denaturation then 45 cycles $\left(94^{\circ} \mathrm{C}\right.$ for $1 \mathrm{~min}, 58^{\circ} \mathrm{C}$ for $30 \mathrm{~s}$ and $72^{\circ} \mathrm{C}$ for $1.5 \mathrm{~min}$ ) amplification with a final extension of $72^{\circ} \mathrm{C}$ for $8 \mathrm{~min}$. The primer pair (HV8-s and HV8-as) was used to amplify (335 base pair) HV8 DNA, the primer pair (CMV-s and CMV-as) was used to amplify (453 base pair) fragment of CMV DNA, the primer pair (EBV-s and EBV-as) was used to amplify (200 base pare) fragment of EBV DNA.

The primer pairs that are illustrated in the following table (B-actin-s and B-actin-as, HSV1-s and HSVlas, HSV2-s and HSV2-as, VZV-s and VZV-as, HV8-s and HV8-as, CMV-s, CMV-as, EBV-s and EBV-as) were used to amplify the requested herpes virus DNA (Table 1).

\section{Statistical analyses}

The statistical analysis was performed using SPSS 21.0 software for windows (SPSS Inc., Chicago, IL, USA). Metric data were described by mean values and standard deviations. Nonmetric data, namely clinical diagnosis, localization, immune status and sex were described by contingency tables and frequency analysis. Appropriate graphs were used to illustrate both types of variables. For the qualitative data analysis $\chi^{2}$-tests 
Table 1 Primers used in the amplification of different human herpesviruses

\begin{tabular}{|c|c|}
\hline Name & Sequences $5^{\prime}-3^{\prime}$ \\
\hline HSV1-S & CAA CTA CCC CGA TCA TCA GTT A \\
\hline HSV1-as & ACA GTT GCC TCC CAT CCG AAA CCA A \\
\hline HSV2-S & CAT CGG CGG TAT TGC GTT TTG GGT A \\
\hline HSV2-AS & CCT ATG AAC TGT CCT AGT TTC C \\
\hline VZV-s & GCT CGT TGA GGA CAT CAA CCG TGT T \\
\hline VZV-as & CAT CGT CGC TAT CGT CTT CAC CAC \\
\hline EBV-s & ACG AGG GGC CAG GTA CAG GA \\
\hline EBV-as & СAC CAT CTC TAT GTC TTG GC \\
\hline CMV-s & CAG CAC САТ ССТ ССТ СТT ССТ CTG G \\
\hline CMV-as & CCA AGC GGC CTC TGA TAA CCA AGC C \\
\hline HV8-s & ATG GAT CCC TCT GAC AAC CTT \\
\hline HV8-as & CGT GGA TCC GTG TTG TCT ACG \\
\hline$B A-s^{a}$ & TTC CCC TCC ATC GTG GGG CGC CCC AGG CAC CAG GGC \\
\hline BA-as & GGC GAC GTA GCA CAG CTT CTC \\
\hline \multicolumn{2}{|c|}{$\begin{array}{l}\text { BA beta actin, HSV1 Herpes simplex virus 1, HSV2 Herpes simplex virus } 2 \\
\text { VZV Varicella zoster virus, EBV Epstein-Barr virus, CMV Cytomegalovirus, } \\
\text { HV8 Human herpesvirus } 8 \\
\text { aprimer for the amplification of beta actin DNA }\end{array}$} \\
\hline
\end{tabular}

or Fisher's exact tests were used. All $p$-values were two tailed and considered statistically significant at $<0.005$.

\section{Results}

\section{Patients and samples}

Basic characteristics of patients and samples are listed in (Table 2).

Altogether 3677 specimens were taken from 3202 patients, who had an average age of 45.6 years $( \pm 20.7$ years); 1597 of the specimens derived from female and 1605 from male patients. In $14.4 \%(n=531)$ of the cases, the specimens came from immunocompromised patients, i.e. $338(9.2 \%)$ of the samples had been taken from human immunodeficiency virus (HIV) infected individuals, 71 (1.9\%) from patients under immunosuppressive therapy due to various reasons, 67 (1.8\%) from bone marrow and 55 samples (1.5\%) from solid organ transplanted patients.

Sample material was mainly swabs $(91.6 \%), 5.5 \%$ were blood samples, the remaining were rinsing liquid, paraffin embedded or native tissue samples and aspirates. In $17.6 \%$ the genital area was the sample site, in $11.9 \%$ and $11.8 \%$, respectively, samples derived from the head/neck area and oral mucosa, followed by the lips (10.7\%) and the eye-region (4.8\%). Further samples originated from the area of the trunk $(8.3 \%)$, the sacrum $(5.5 \%)$, the abdomen $(2.1 \%)$, the flank (1.3\%), upper limbs (4.0\%) and lower limbs (4.4\%). A small proportion of the samples derived from the fingers and the inguinal region. In $9.8 \%$ the sample site was not listed in the files.
Table 2 Basic characteristics of patients and samples

\begin{tabular}{|c|c|}
\hline Number of patients & 3202 \\
\hline \multicolumn{2}{|l|}{ Gender } \\
\hline Male & $1605(50.1 \%)$ \\
\hline Female & $1597(49.9 \%)$ \\
\hline \multicolumn{2}{|l|}{ Age (years) } \\
\hline Average \pm SD & $45.6 \pm 20.7$ \\
\hline Range & $0-99$ \\
\hline Number of samples & 3677 \\
\hline \multicolumn{2}{|l|}{ Samples derived from } \\
\hline Immunocompetent patients & $3146(85.6 \%)$ \\
\hline HIV-positive patients & $338(9.2 \%)$ \\
\hline Patients under immunosuppressive drugs & $71(1.9 \%)$ \\
\hline Bone marrow transplant patients & $67(1.8 \%)$ \\
\hline Solid organ transplant recipients & $55(1.5 \%)$ \\
\hline \multicolumn{2}{|l|}{ Sample material } \\
\hline Swabs & $3369(91.6 \%)$ \\
\hline Blood sample & $203(5.5 \%)$ \\
\hline Rinsing liquid & $69(1.9 \%$ \\
\hline Tissue & $35(1.0 \%)$ \\
\hline Liquid aspirate & $1(0.0036 \%)$ \\
\hline \multicolumn{2}{|l|}{ Sample sites } \\
\hline Genital area & $647(17.6 \%)$ \\
\hline Head and neck area & $437(11.9 \%)$ \\
\hline Oral mucosa & $435(11.8 \%)$ \\
\hline Lips & $393(10.7 \%)$ \\
\hline Trunk & $307(8.3 \%)$ \\
\hline Blood & $203(5.5 \%)$ \\
\hline Sacral/gluteal & $202(5.5 \%)$ \\
\hline Eye region & $176(4.8 \%)$ \\
\hline Lower limbs & $161(4.4 \%)$ \\
\hline Upper limbs & $146(4.0 \%)$ \\
\hline Abdomen & $79(2.1 \%)$ \\
\hline Flank & $49(1.3 \%)$ \\
\hline Fingers & $35(1.0 \%)$ \\
\hline Inguinal region & $23(0.6 \%)$ \\
\hline Not known & 362 (9.8\%) \\
\hline Others & $22(0.6 \%)$ \\
\hline
\end{tabular}

In clinical practice at the dermatology department, swabs from herpetiform lesions from the skin and mucous membranes, were not only analyzed for HSV-1 and HSV-2, but the analysis was routinely combined with that for VZV. This was the case for 3015 samples out of the 3677 specimen, which is referred to as testing for the triplet HSV-1, HSV-2 and VZV. Half of the samples tested for the triplet were tested negative for all three viruses $(n=1437,47.7 \%)$. In $18.2 \%$ of the tested samples $(n=550)$ HSV- 1 was verified, in $11.3 \%(n=341) \mathrm{HSV}-2$ and in $22.8 \%(n=687) \mathrm{VZV}$ was detected. 
Fig. 1 PCR results for the triplet (HSV-1, HSV-2, VZV) for the different clinical diagnoses categorized based on similarities of the clinical manifestation mentioned on

the order form

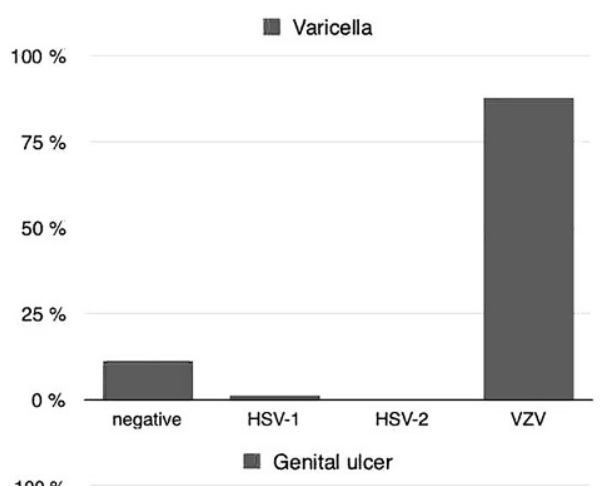

$100 \%$

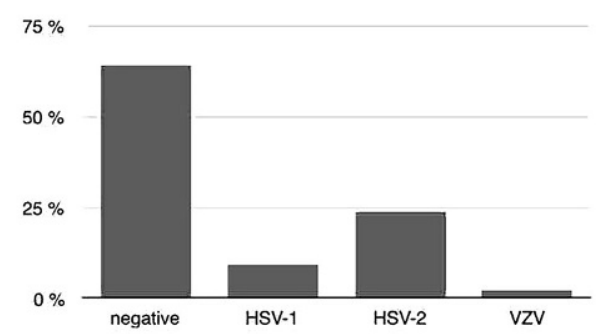

$100 \%$

- Herpes zoster

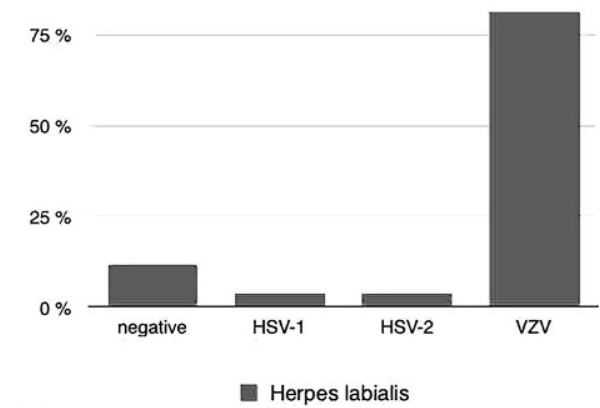

$100 \%$

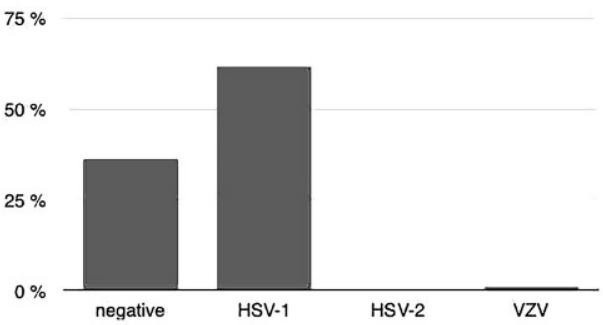

$100 \%$

Eral ulcer

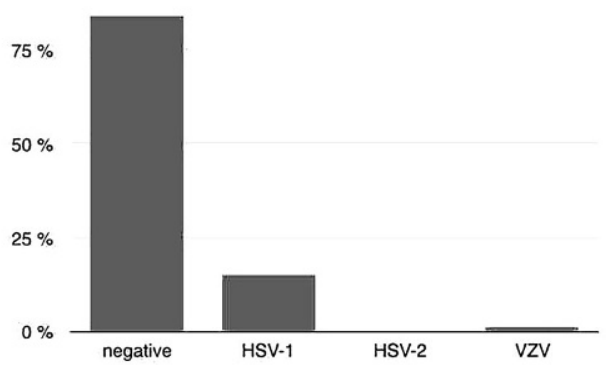

$100 \%$

- Genital herpes

$75 \%$

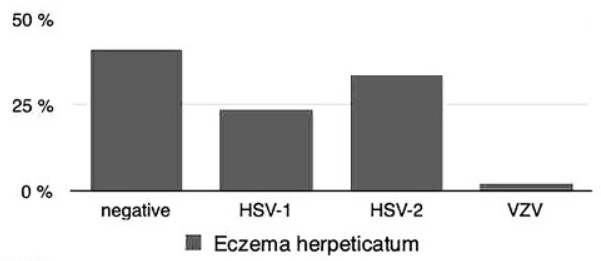

$100 \%$

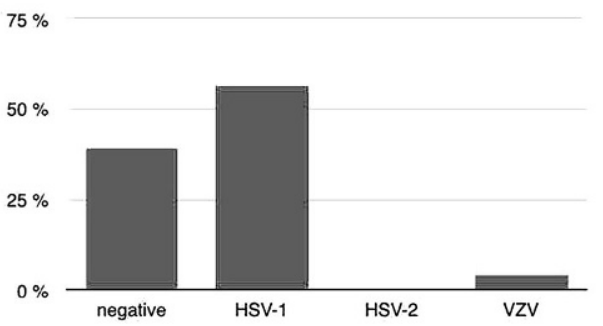

$100 \%$

- Herpes infection

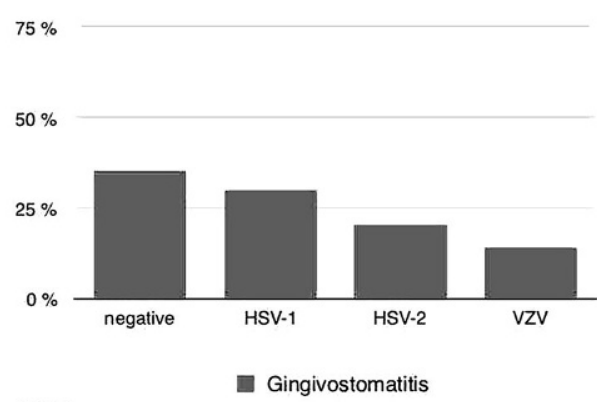

$100 \%$

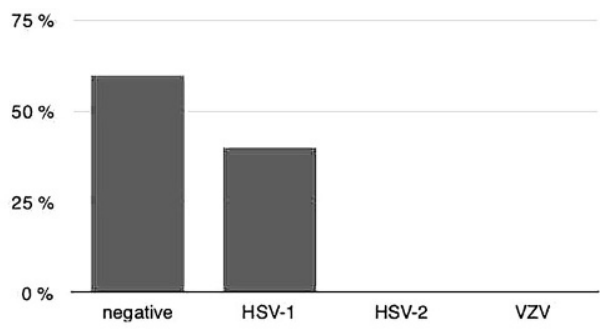

$100 \%$

- Herpetic keratokonjunctivitis

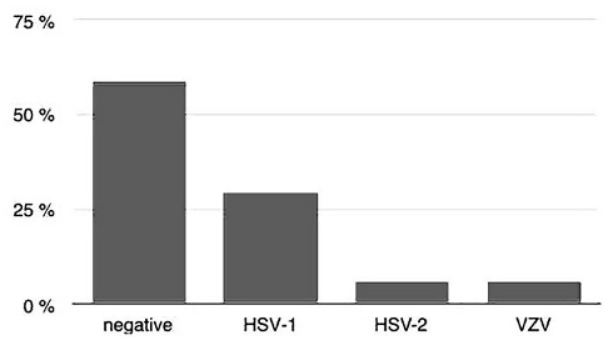


Suspected clinical diagnoses in association with the test results

A high correlation rate was found between the clinical diagnosis of varicella $(87.5 \%)$ and the proof of the suitable causative agent, namely VZV. In those cases where explicitly genital, gluteal or recurrent genital herpes was cited in the charts, the investigation gave a positive PCR result in $59.1 \%$, either for HSV-1 (23.7\%) or HSV-2 $33.3 \%)$ or VZV (2.1\%). A similar constellation was observed for a similar clinical diagnosis given in the order form, namely genital ulcer in 42 patients, which led to a positive PCR result in $35.7 \%$ of the cases, for HSV-1 in 9.5\%, for HSV-2 in $23.8 \%$ and for VZV 2.4\% (for details see Fig. 1). The 42 swabs derived from 21 women and 21 men and positive PCR results were more often found in women (57.9\%), than men $(42.1 \%)$. The majority $(68.4 \%)$ of the positive results derived from immunocompetent patients, whereas $31.6 \%$ were immunosuppressed due to various reasons ( $10.5 \%$ HIV, $5.3 \%$ bone marrow transplant, $15.8 \%$ organ transplant), 7 patients with genital ulcer disease, negative for the triplet, were additionally tested for EBV and 23 for CMV and for each of those viruses, 2 patients tested positive.

The diagnosis of eczema herpeticatum was supported by the proof of HSV-1 from a lesion swab in $56.5 \%$; no samples tested positive for HSV-2 in this scenario, whereas a small percentage $(4.3 \%)$ were positive for VZV.

The clinical diagnosis of herpes zoster corresponded well with the proof of VZV in $81.3 \%$ of the cases. When the clinical investigator had sent samples from any site of a clinically herpetic lesion, excluding the genital or oral region, specified with the diagnosis herpes infection, a positive result was achieved for HSV-1 in $30.0 \%$, for HSV-2 in $20.6 \%$ and for VZV in $14.1 \%$, with a total of $64.7 \%$ positive results. The classical diagnosis of labial herpes was supported by an exclusively positive PCR for HSV-1 in $61.9 \%$, the same applied for the scenario where the clinicians stated (aphthous) gingivostomatitis or oral ulcer, corresponding to positive PCR results for HSV-1 in $40.0 \%$ and $15.0 \%$, respectively, but no HSV-2 and VZV could be isolated only on one occasion. Eventually these samples derived from patients with primary HSV-1 infections. Swabs from lesions with the diagnosis herpetic keratoconjunctivitis led to a positive PCR result in $41.2 \%$; in $29.4 \% \mathrm{HSV}-1$, in $5.9 \% \mathrm{HSV}-2$ and in $5.9 \%$ VZV were isolated.

With respect to the PCR results for HSV-2 in general (either positive or negative), an equal male to female ratio was observed in this cohort, whereas there was a shift of the ratio to 1:1.3 towards the female population in those who tested positive for HSV-2, regardless of the sample site or the stated diagnosis. This result was borderline statistically significant $\left(\chi^{2}\right.$-test; $p=0.042$, data not shown). Apart from that $23.7 \%$ of all HSV-2 positive results were found in samples from
HIV positive individuals, whereas only $10.8 \%$ of the samples originated from immunocompetent patients. This difference was statistically significant $(p<0.002)$. Among the patients with a positive PCR result for one of the viruses of the triplet, a male to female ratio of $4: 6$ was observed and one third $(31.6 \%)$ of the patients were immunocompromised, $10.5 \%$ of them being medically immunosuppressed, $15.8 \%$ HIV positive and $5.3 \%$ bone marrow transplanted.

\section{Discussion}

Over a 4-year period 3677 mostly cutaneous and mucocutaneous specimens from patients were submitted for testing using an in-house PCR. A high correlation between the suspected clinical diagnosis and the PCR result was found, especially for skin manifestations with distinct clinical manifestations compatible with herpetic pathogenesis. Diagnoses such as cold sore, shingles or chickenpox had a high correlation rate with a positive PCR result ranging from $60 \%$ to $88 \%$. A significant difference was found between the HSV-2 detection rate in the HIV positive and the HIV negative cohort regardless of the sample site, as the HSV-2 detection rate was two times higher in the HIV positive patient. This observation is supported by a number of other publications [7-9]. Genital herpes has played a more important role than any other sexually transmitted infection in driving HIV prevalence not only in Africa $[10,11]$. As the herpes simplex virus breaks down the epithelium, these microdisruptions serve as a portal for the entry of HIV. Additionally, HSV-2 infected epithelial cells secrete cytokines, which attract immune cells such as dendritic and Langerhans cells. These cells serve as targets and promote the acquisition of HIV [12, 13]. Previous studies have shown that people suffering from HIV and recurrent genital herpes with HSV-2 reactivation, have a higher HIV transmission rate [14].

In this study population, HSV-2 could be significantly more frequently detected in women than in men (1.3:1). This finding is supported by similar observations by other investigators $[15,16]$, e.g. Looker et al. reported a female to male ratio of 1.8:1 [17]. This difference might be explained by female sex hormones being risk factors for the acquisition of sexually transmitted viral diseases, such as HSV-2 in an animal model [18].

There were 42 patients presenting with the clinical diagnosis genital ulcer disease, characterized by a single ulcer bigger than a typical herpetic skin lesion. Only $35.7 \%$ of the samples obtained from these lesions tested positive for HSV-1, HSV-2 or VZV, where HSV-1 was detected in 4, HSV-2 in 10 patients and VZV in 1 patient; in 2 patients CMV and another $2 \mathrm{EBV}$ was proven. The high number of negative PCR results indicated that the majority of genital ulcer diseases were due to other reasons, including infection with Treponema pallidum, non-infectious diseases such as au- 
toimmune bullous diseases, Behcet's disease or fixed drug eruptions [19]. In this study $10.5 \%$ of the patients with genital ulcer disease due to herpes virus infection were HIV positive, equally distributed among males and females, other studies showed higher HIV rates ranging from $27 \%$ to $40 \%$ [20, 21]. The relatively low number found in this study indicates that the study population represents an average common population, rather than a subset of individuals with high risk sexual behavior.

The in-house PCR method with simply applying material onto a slide is robust, not being influenced by transport or storage and supplying a sufficient amount of viral DNA. Therefore, the method could be an option in low-budget developing countries.

In summary, distinct clinical diagnoses have a high correlation rate with a positive PCR result. A significantly higher rate of HSV-2 positive results was found in HIV positive patients and women. The data illustrate that the direct proof of herpes viruses has a high diagnostic value, especially in daily clinical life.

Acknowledgements The authors would like to express their deep gratitude to Aumaid Uthman, PhD. Special thanks go to him for the development of the herpes virus-specific polymerase chain reaction at the Department of Dermatology. We would also like to extend our thanks to the technicians of the laboratory, Susanne Drexler and Christopher Nava, for their work.

Funding Open access funding provided by Medical University of Vienna.

\section{Compliance with ethical guidelines}

Conflict of interest V. Schremser, L. Antoniewicz, E. Tschachler, and A. Geusau declare that they have no competing interests.

Ethical standards All procedures performed in studies involving human participants were in accordance with the ethical standards of the institutional and/or national research committee and with the 1975 Helsinki declaration and its later amendments or comparable ethical standards. The study was approved by the ethics committee of the Medical University of Vienna (EK-number 2168/2013).

Open Access This article is distributed under the terms of the Creative Commons Attribution 4.0 International License (http://creativecommons.org/licenses/by/4.0/), which permits unrestricted use, distribution, and reproduction in any medium, provided you give appropriate credit to the original author(s) and the source, provide a link to the Creative Commons license, and indicate if changes were made.

\section{References}

1. Oxford J, Kellam P, Collier L. Human virology influenza. In: Human virology. 5th ed. Oxford: Oxford University Press; 2016. pp. 142-55.

2. Goldman BD. Herpes serology for dermatologists. Arch Dermatol. 2000;136:1158-61.
3. Singh A, Preiksaitis J, Ferenczy A, et al. The laboratory diagnosis of herpes simplexvirus infections. Can JInfectDis Med Microbiol. 2005;16:92-8.

4. Aliabadi N, Jamalidoust M, Asaei S, et al. Diagnosing of herpes simplex virus infections in suspected patients using real-time PCR. Jundishapur J Microbiol. 2015;8:16-27.

5. LeGoff J, Péré H, Bélec L. Erratum to: Diagnosis of genital herpes simplex virus infection in the clinical laboratory. Virol J.2015;12:167.

6. World Health Organisation. WHO guidelines for the treatment of genital herpes simplex virus. 2016. http://www. who.int/reproductivehealth/publications/rtis/genitalHSV-treatment-guidelines/en/. Accessed 2 Jan 2017.

7. Romanowski B, Myziuk LN, Walmsley SL, et al. Seroprevalence and risk factors for herpes simplex virus infection in a population of HIV-infected patients in Canada. Sex Transm Dis. 2009;36:165-9.

8. Russell DB, Tabrizi SN, Russell JM, et al. Seroprevalence of herpes simplex virus types 1 and 2 in HIV-infected and uninfected homosexual men in a primary care setting. JClin Virol. 2001;22:305-13.

9. Freeman EE, Weiss HA, Glynn JR, et al. Herpes simplex virus 2 infection increases HIV acquisition in men and women: systematic review and meta-analysis of longitudinal studies. AIDS. 2006;20:73-83.

10. Abu-Raddad LJ, Magaret AS, Celum C, et al. Genital herpes has played a more important role than any other sexually transmitted infection in driving HIV prevalence in Africa. Plos One. 2008; https://doi.org/10.1371/journal.pone. 0002230.

11. Looker KJ, Elmes JAR, Gottlieb SL, et al. Effect of HSV-2 infection on subsequent HIV acquisition: an updated systematic review and meta-analysis. Lancet Infect Dis. 2017;17:1303-16.

12. Duluc D, Gannevat J, Anguiano E, et al. Functional diversity of human vaginal APC subsets in directing T-cell responses. Mucosal Immunol. 2013;6:626-38.

13. Zhu J, Hladik F, Woodward A, et al. Persistence of HIV-1 receptor-positivecells after HSV-2 reactivationis a potential mechanism for increased HIV-1 acquisition. Nat Med. 2009;15:886-92.

14. Todd J, Riedner G, Maboko L, et al. Effect of genital herpes on cervicovaginal HIV shedding in women co-infected with HIV AND HSV-2 in Tanzania. Plos One. 2013; https://doi. org/10.1371/journal.pone.0059037.

15. Rajagopal S, Magaret A, Mugo N, et al. Incidence of herpes simplexvirus type 2 infections in Africa: a systematic review. Open Forum Infect Dis. 2014; 1:ofu43.

16. Nakku-Joloba E, Kambugu F, Wasubire J, et al. Sero-prevalence of herpes simplex type 2 virus (HSV-2) and HIV infection in Kampala, Uganda. Afr Health Sci. 2014;14:782-9.

17. Looker KJ, Magaret AS, Turner KME, et al. Global estimates of prevalent and incident herpes simplex virus type 2 infections in 2012. Plos One. 2015;10:e114989.

18. Kaushic C, Roth KL, Anipindi V, et al. Increased prevalence of sexually transmitted viral infections in women: the role of female sex hormones in regulating susceptibility and immune responses. J Reprod Immunol. 2011;88:204-9.

19. Sehgal VN, Pandhi D, Khurana A. Nonspecific genital ulcers. Clin Dermatol. 2014;32:259-74.

20. Suntoke TR, Hardick A, Tobian AAR, et al. Evaluation of multiplex real-time PCR for detection of Haemophilus ducreyi, Treponema pallidum, herpes simplex virus type 1 and 2 in the diagnosis of genital ulcer disease in the Rakai District, Uganda. Sex Transm Infect. 2009;85:97-101. 
21. Hope-Rapp E, Anyfantakis V, Fouéré S, et al. Etiology of genital ulcer disease. A prospective study of 278 cases seen in an STD clinic in Paris. Sex Transm Dis. 2010;37:153-8.

Publisher's Note Springer Nature remains neutral with regard to jurisdictional claims in published maps and institutional affiliations. 